\title{
The Extracellular Matrix Protein 1 (ECM1) in Skin Biology: An Update for the Pleiotropic Action
}

\author{
Noritaka Oyama $^{*}, 1$ and Joseph Merregaert ${ }^{2}$ \\ ${ }^{I}$ Division of Dermatology and Dermato-Allergology, Matsuda General Hospital, Ohno, Fukui 912-0026, Japan \\ ${ }^{2}$ Emeritus Professor at the University of Antwerp, Department of Biomedical Sciences, Universiteitsplein 1, 2610 \\ Wilrijk, Belgium
}

\begin{abstract}
Extracellular matrix protein 1 (ECM1) is a secreted glycoprotein that plays a pivotal role in the structural and homeostatic biology of the skin, particularly in angiogenesis, reconstitution of basement membrane, proliferation and differentiation of epidermal keratinocytes and dermal fibroblasts, and malignant transformation. This rationale is substantiated by loss-of-function mutations in the ECM1 gene in an autosomal recessive genodermatosis lipoid proteinosis and circulating IgG autoantibodies to this molecule in a humoral autoimmune condition lichen sclerosus, both of which are counterpart disease conditions sharing comparable skin pathology. In the recent decade, considerable progress has been made in determining the in vivo function of ECM1 in animal model studies. Furthermore, underlying insights arose for the genetic predisposition in inflammatory bowel disease ulcerative colitis, acquisition of immune tolerance and allergic responses via particular $\mathrm{T}$ cell subsets such as CD4+CD25+ regulatory $\mathrm{T}$ cells and Th2 cells, regeneration of certain organs, and clinical advantages for diagnostic and prognostic significance in various cancers. Following our latest review in 2009, we now update the most recent evidences for the pleiotropic action of ECM1 in skin research, and also highlight the novel pathogenic relevance of this molecule in a variety of human disorders.
\end{abstract}

Keywords: Extracellular matrix, protein 1 (ECM1), pleiotropic action.

\section{INTRODUCTION}

An increasingly large number of gene defects and autoantibodies has been linked to specific heritable and autoimmune disorders with skin manifestations. In fact, pathogenic mutations are now known to present in over 500 different genes in a manner that these genetic variations help to explain the characteristic phenotypes of certain heritable diseases with skin involvement [1-3]. The genodermatosis mutation database has been available and apparently revealed both candidate genes and predictable skin manifestations [4]. Of these, investigation for pair of genetic abnormalities and autoimmunity targeting the same molecule in skin may often explore the underlying insight of the molecular-based pathogenesis. One of the exciting candidates for such an association is the extracellular matrix protein 1 (ECM1).

ECM1 is an $85-\mathrm{kDa}$ secreted glycoprotein that was first identified in the conditioned medium from the murine osteogenic stromal cell line MN7 [5,6]. It was termed extracellular matrix protein 1 because of the isolation from a variety of connective tissue proteins, such as type I collagen, osteopontin, osteonectin, cathepsin $\mathrm{B}$ and $\mathrm{L}$, and bone sialo protein. Thereafter, the human ECM1 homolog was characterized [7,8]; the gene is located on chromosome 1q21.2 and encodes four splice variants, ECM1a-d. ECM1a

*Address correspondence to this author at the Division of Dermatology and Dermato-Allergology, Matsuda General Hospital, Ohno, Fukui 912-0026, Japan; Tel: +81-(0)779-66-3238; Fax: +81-(0)779-66-6098;

E-mail: norider@wine.plala.or.jp
(1.8 kb, $540 \mathrm{aa)}$ comprises 10 exons, whereas ECM1b (1.4 $\mathrm{kb}, 415 \mathrm{aa})$ lacks exon 7 and ECM1c (1.85 kb, $559 \mathrm{aa})$ contains an additional exon 5a within intron 5 , which shares high homology with exon 6 of murine ECM1 [9]. These three major variants show wide-spread and different expression patterns in human tissues $[7,9,10]$. ECM1a is expressed in the vast majority of organs, including skin, liver, intestine, lung, ovary, prostate, testis, skeletal muscle, pancreas, and kidney, albeit greater expression levels in placenta and heart. In contrast, ECM1b has an extremely restricted expression in tonsils and epidermal keratinocytes, and tissue-specific expression of ECM1c has yet to be fully identified except for skin [11]. ECM1d comprises a splicing variant, with an out of frame insertion of 71 nucleotides at the $5^{\prime}$ end of exon 2, resulting in a truncated protein of 57 amino acids [12], whose biological significance and in vivo expression is still unknown. In skin, ECM1 a was expressed in the epidermal basal layer, dermal blood vessels, the outer root sheath of hair follicles, sebaceous lobules, and sweat gland epithelia, whereas ECM1b was in the suprabasal layers of epidermis $[10,11,13]$. Thus, in vivo association between each ECM1 splicing variant and skin biology has gradually been defined.

The ECM1 protein contains a signal peptide of 19 amino acids, followed by four domains: a cysteine-free $\mathrm{N}$-terminal segment, two tandem repeats and a C-terminal fragment. The two tandem repeat domains and the $\mathrm{C}$-terminal domain contain a specific cysteine arrangement, $\mathrm{C}-\left(\mathrm{X}_{12-38}\right)-\mathrm{CC}-\left(\mathrm{X}_{7}\right.$ 10)-C [6,7]. More recently, a computational model for the three-dimensional structure of ECM1a was determined in 
order to identify putative region(s) for binding with candidate partners in human skin [14]. Functional studies have revealed the biological significance of ECM1 in angiogenesis, endochondral bone/cartilage development, and malignancies. A series of these evidences has followed the concept of the early observation for the multifactorial action of ECM1 in various organs and tissues. Most of these biological activities represent the positive regulation for cell proliferation, migration, and differentiation, finally resulting in tissue formation, but inversely show negative effects on chondrocyte hypertrophy, matrix mineralization, and endochondral bone formation [13-17]. On the other hand, the pathogenic impairment of ECM1 function has recently been demonstrated in human genetic and autoimmune disorders, lipoid proteinosis (LiP) and lichen sclerosus (LS), respectively $[18,19]$, providing further understanding of in vivo ECM1 biophysiology. These discoveries led to the progress in several trials for recapitulating both disease conditions by gene knockout and antibody transfer experiments for ECM1 [20,21]. Main stream of these evidences has been addressed in the 2009-review article [22]. In this review, we focus on the most updated evidences of the ECM1 function in skin research, and also highlight the novel pathogenic potency of this molecule in the genetic background of inflammatory bowel diseases, $\mathrm{T}$ celldependent allergic responses, cancer biology, and skin ageing.

\section{GENETIC AND AUTOIMMUNE IMPAIRMENT OF ECM1 FUNCTION}

\section{Lipoid Proteinosis and ECM1}

\section{Clinics and Skin Pathology}

LiP (OMIM 247100), also known as Urbach-Wiethe disease or hyalinosis cutis et mucosae $[23,24]$, is an autosomal recessive mucocutaneous disorder caused by lossof-function mutation of ECM1 gene [19]. The disease is characterized by hoarse voice, generalized thickening and scarring of the skin and mucosae (Fig. 1) [23-25]. Hyperkeratosis and pronounced infiltration are obvious in regions exposed to mechanical stimuli or trauma, such as eyelids, dorsa of hands and feet, elbows, knees, axillae, and buttocks, clinically resembling with verruciform skin. Other underrecognized skin features include photosensitivity [26,27], thus being manifested as Koebner's and photoKoebner's phenomena. Normally, the LiP skin do not undergo a delayed wound healing or keroids during the clinical course, implicating that ECM1 deficiency does not participate in the wound healing process, or otherwise can be at least compensated. Extracutaneous manifestations include opthalmological features [28], epilepsy ( $25 \%$ of all cases), and various neuropsychiatric symptoms, such as dystonia, or impairment of memory, perception and emotional control, perhaps in association with cerebral calcification [25,29-34]. Among a variety of these manifestations, the most reliable clinical hallmarks are hoarse voice from an early childhood and a limited protrusion of the tongue [27]. Therapies are mostly unhelpful. Recent progress for the treatment option includes oral retinoid acitretin that was challenged to three patients, but the clinical efficacy is limited; of the three patients, one showed an improvement of hoarseness and indurative skin lesion [35], and the other two had some regression and softening of the skin induration [36].

\section{Update of the ECM1 Gene Mutation Database}

Following the latest review of 41 mutations in the ECM1 gene in LiP individuals and families in 2007 [27], the addition of 21 pathogenic mutations to the database has been reported. Of these, only 4 were novel and different mutations [37-41], with the exception that only one case shares the c.1019delA heterozygous mutation published previously in a Kuwait patient [18] and the C269Y homozygous mutation was recurred between patients in the Middle East countries (Table 1) $[39,40]$. All the remaining were recurrent mutations reported elsewhere. Thus, the combined mutation database now contains up to 45 different mutations of the ECM1 gene [27, this review]. Overall mutation characters vary considerably; for example, nonsense/missense, frame shift, different sizes of deletion and insertion, or splice site mutations. These mutations span throughout all the 10 exons, except for exon 5a, but more than half of all mutations $(25 / 45,56 \%)$ occur within exons 6 or 7 (including adjacent splice sites). These findings favor the hypothesis that: i) epitope(s) within exons 6 and 7 represent the plausible target for the establishment of LiP phenotype, ii) ECM1a and c (isoforms containing exons 6 and 7) are of much more biological significance than ECM1b (an alternative splicing isoform lacking exon 7).

Clinically, hoarse voice and protrude tongue were found in all cases with the novel 4 mutations (Table 1), highlighting the clinical hallmark manifestations in LiP. Looking back to the updated ECM1 gene mutations and clinicopathology of the affected individuals, however, there seems no apparent genotype-phenotype correlation, even in familial and sibling cases with the same mutations, as being comparable with the latest review [27]. Therefore, the variable clinical manifestations of LiP are more likely to be a consequence of the different acquired settings in each case.

Table 1. Characters of the Updated ECM1 Gene Mutation in Lipoid Proteinosis

\begin{tabular}{|c|c|c|c|c|}
\hline Mutation(s) & Site of Mutation(s) & Geographical Origin & Hoarseness/Protrude Tongue & Reference \\
\hline \hline c.240delTC/c.1019delA & Exon 4/exon 7 & Arabian & $+/+$ & {$[37]$} \\
\hline p.Q206X/p.Q206X & Exon 6 & Pakistani & $+/+$ & {$[38]$} \\
\hline p.C269Y/p.C269Y & Exon 7 & Saudi Arabian, Iranian & $+/+$ & {$[39,40]$} \\
\hline p.C477R/p.C477R & Exon 9 & Chinese & {$[41]$} \\
\hline
\end{tabular}

${ }^{1}$ The heterozygous mutation c.1019delA has been published previously in a Kuwait patient [18].

${ }^{2}$ The homozygous mutation C269Y was recurred between patients in the Middle East countries $[39,40]$. 


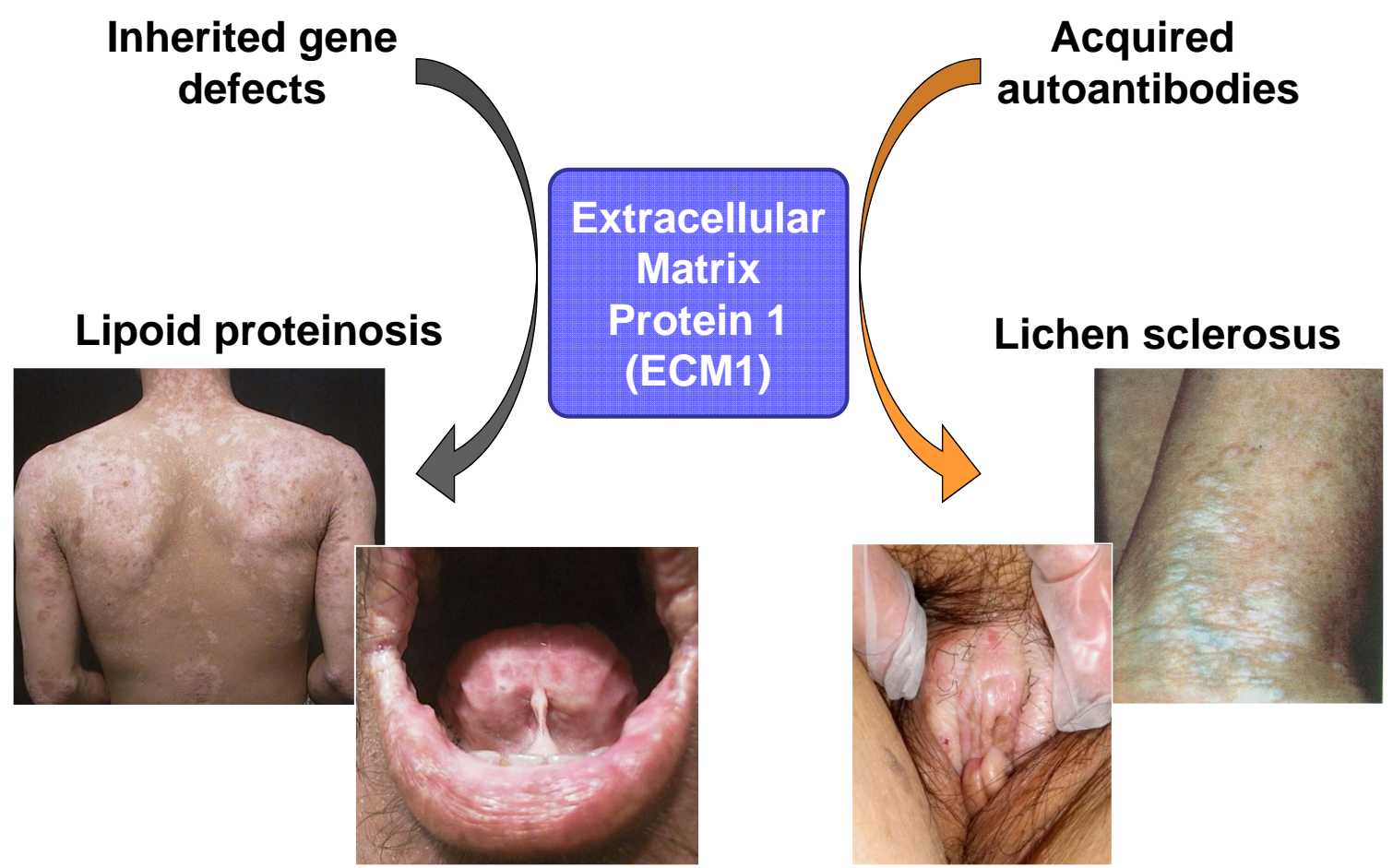

Fig. (1). A counterpart disease concept for genodermatosis LiP and autoimmune condition LS, both of which target ECM1. LiP and LS are considered a disease entity for genetical and immunological impairment of ECM1 function, respectively [18,19]. Both diseases have considerable overlapping of the skin clinicopathology; trauma-induced inflammation (Koebner's phenomenon) and microscopic findings such as epidermal atrophy with hyperkeratosis, disruption and duplication of the basement membrane, and hyaline (glassy) changes and telangiectasia in the upper dermis $[25,27,42,43,64]$. The use of all clinical photographs was permitted by the corresponding patients according to the approval of the institutional board of Matsuda General Hospital.

\section{Lichen Sclerosus and ECM1}

\section{Clinics}

The breakthrough discovery of ECM1 gene mutations in LiP led to open another window for humoral autoimmunity to this molecule in LS [19]. LS is an acquired chronic inflammatory disorder that affects skin and mucous membranes, with highly occurrence in anogenital area [42]. In a large cohort retrospective study and review of previous reports, extragenital LS alone may occur in approximately $15 \%$ of all cases investigated $[43,44]$. As a constant observation including most recent cross-sectional studies, the disease prevalence ranges from $0.1-0.3 \%$, with a male to female ratio of $1: 10[43,45,46]$. Clinical features include erosions, pale patches, papulo-plaques, and porcelain-like atrophic scarring with intractable itching and soreness (Fig. 1), thus causing dysuria, sexual dysfunction, and physical morbidity. There is also an increased risk of squamous cell malignancy in longstanding lesions $[43,47]$. In female LS, twin age peaks (prepubertal/postmenopausal) suggest a hormonal origin in the pathogenic background, but hormone therapy was mostly unsatisfactorily [47].

\section{Scenario for Autoimmunity to ECM1 in LS}

The progress for screening of disease-specific autoantibodies in LS is based on the considerable prominence for possible genetic susceptibility and humoral autoimmune basis to the disease [48-50]. Reports have shown variable intra-familial cases with $\operatorname{LS}[51,52]$, an association with particular HLA class II antigens DQ7-9 $[53,54]$, and an increased incidence of various autoimmune diseases and autoantibodies, such as morphea, thyroiditis, pernicious anaemia, type I diabetes mellitus, alopecia areata, vitiligo, bullous pemphigoid and mucous membrane pemphigoid [46,55-61]. A hundred years ago, evidence implicating a humoral autoimmune response in LS has been demonstrated in a case with probable LS, being induced by injection of serum from an affected individual into nonlesional skin [62]. More significantly, LS has considerable overlapping of the skin clinicopathology in an ECM1deficient genodermatosis LiP; for example, trauma-induced inflammation (Koebner's phenomenon) [27,63] and microscopic findings such as epidermal/epithelial atrophy with hyperkeratosis, disruption and thickness of basement membrane, and hyaline (glassy) changes and teleangiectasia in the upper dermis $[27,42,43,64]$.

Immunoblotting and an antigen-specific ELISA have identified serum IgG antibodies to ECM1 in $74-80 \%$ of female patients with genital LS, with $94 \%$ specificity in discriminating LS from other autoimmune diseases and healthy control [21]. Interestingly, higher titers of antiECM1 antibodies correlated with more longstanding and refractory diseases, and cases complicated by squamous cell carcinoma. Also, a reliable number of male patients with penile LS $(n=80)$ tend to have higher titers of serum anti- 
ECM1 antibodies than age-matched normal males [65]. For an immunological background, male LS patients have a relatively lower prevalence of associated autoimmune and autoantibody disorders in comparison with female LS patients [66,67]. Thereafter, several case reports have revealed the presence of serum anti-ECM1 antibodies in LS with different clinical features, particularly extragenital lesions $[68,69]$. These evidence series provide further weight for a humoral autoimmunity to ECM1, without regard to genders and disease phenotype, being a pathogenic axis in LS.

\section{ECM1 PROTEIN STRUCTURE AND ITS BINDING PARTNERS}

A computationally predicted three-dimensional structure of the ECM1 a protein revealed further detailed insight for a disease-specific impairment of ECM1 function in LiP and LS. ECM1 a protein can be divided into 4 distinct domains (Fig. 2B); the first domain consists mainly of $\alpha$-helices $(\alpha D 1)$, while the three remaining domains, namely Serum Albumin SubDomain-Like domains 2-4 (SASDL), were topologically comparable with the subdomain of the third serum albumin domain [14]. SASDL2 and SASDL3 are capable of binding with most of the extracellular matrix proteins identified so far, e.g., laminin 332, fibulin 1C/D and 3 , and matrix metalloproteinase-9 (MMP-9), phospholipid scramblase 1 (PLSCR1), while the C-terminus of ECM1 interacts specifically with perlecan and cartilage oligomeric matrix protein (COMP) (Fig. 2A) [11,14,70-74]. These ECM1-protein interaction partners have been identified by yeast two hybrid (Y2H) library screening or ELISA-based methods (e.g. fibronectin, type IV collagen), while ECM1carbohydrate interactions were established through in vitro binding experiments (hyaluronic acid, chondroitin sulphate A, heparin) (Fig. 2A). Most of these binders co-localize immunohistologically with ECM1 in human skin.

COMP is a 524-kDa pentameric, disulfide-bonded glycoprotein that represents a prominent non-collagenous component of cartilage extracellular matrix. It is expressed in tendon, bone (osteoblasts only), and synovium [75,76]. Mutations in the human COMP gene cause the development of pseudo-chondroplasia and multiple epiphyseal dysplasia, autosomal-dominant forms of short limb dwarfism characterized by short stature, normal facies, epiphyseal abnormalities, and early onset osteoarthritis [77], thus implicating the pivotal roles in osteo-chondrogenesis and matrix mineralization. Perlecan is a major heparan sulfate proteoglycan that is involved in the binding and crosslinking with basement membrane and interstitial dermal components, such as laminins, fibronectin, type IV collagen, fibulin-2, and heparin [78,79]. PLSCR1 is an endofacial plasma membrane protein believed to carry out calciumdependent nonspecific and bidirectional movement ("scrambling") of phospholipids across the plasma membrane, contributing to cell proliferation/differentiation and apoptosis via direct interaction with epidermal growth factor (EGF), platelet-derived growth factor (PDGF), fibroblast growth factor (FGF-7, vascular endothelial growth factor (VEGF), and caspase [80-83]. Moreover, ECM1 can bind to both collagen IV and laminin-332 (formerly designated as laminin-5, which consists of $\alpha 3, \beta 3$, and $\gamma_{2}$ sub-chains) and also enhances their binding $[14,70]$.
All of these binders are regular constituents of the basement membrane, its surrounding interstitials, and appendages in the skin, which possess a large regulatory potency for enhancing and reducing functions, depending on the cellular or tissue context (Fig. 3a). On this basis, ECM1 can be a multifunctional binding core and/or a scaffolding protein, acting as a "biological glue" by its promiscuous interaction with a variety of extracellular and structural proteins, thereby contributing to the maintenance of skin integrity and homeostasis [70, 84-86]. Hence, disruption of the ECM1 function may cause the failure of multicommunication among the surrounding skin structural and interstitial molecules, resulting in the torsion of lamina lucida/densa [64] and lamellate or punctuated structures below basement membrane, accompanied by excess deposition of collagens IV and laminin-332, perlecan, extracellular matrixes around the thickening blood vessel walls $[85,86]$, and disorganization of type VII collagen [64], a major constituent of anchoring fibril for skin basement membrane, as seen in LiP and LS skin pathology (Fig. 3b).

\section{DIFFERENCES IN MOLECULAR-BASED PATHO- MECHANISM BETWEEN LIP AND LS}

Conceptionally, genodermatosis LiP and acquired autoimmune condition LS can be recognized a counterpart disease condition targeting ECM1 (Fig. 1) [18,19]. Considering ECM1 protein structure and its corresponding interaction partners, however, the pathomechanism of ECM1 function impairment in both diseases would be different. Combined with the ECM1 gene mutation database [27, this review], the hot spot region for ECM1 gene mutations in LiP patients (exons 6 and 7) lies within the complete SASDL 2 and part of SASDL 3 (aa177-aa361, Fig. 2B, C) [14,70]. Notably, most of these mutations are non-sense or out-offrame changes, causing deletion of SASDL2 and its downstream region. In contrast, epitope mapping studies revealed that most of detectable IgG antibodies to ECM1 in LS patients' sera react with both NH2- (32-203aa) and COOH-terminal ends (349-480aa) of ECM1 epitopes, just avoiding the SASDLs 2 and 3 (Fig. 2B) [21]. This illustrates a heterogeneous $\operatorname{IgG}$ reactivity to "spared" antigenic epitopes within ECM1 protein. Together with basic research data, one may speculate that anti-ECM1 antibodies in LS mainly affect the functional binding of ECM1 with type IV collagen, COMP, and perlecan, whereas LiP mutations affect laminin 332, PLSCR1, fibulines-1C/D and -3, MMP-9, COMP, and perlecan interactions (Fig. 2A) $[11,14,42,70-74]$. The differences in the affected binding partners between both diseases may cause other subtle microscopic changes; the granular material composed of type VII collagen, a major component of anchoring fibrils in the sublamina densa, was deposited in the dermis of LS skin, but almost restricted to the dermal periappendage regions in LiP skin [64]. The ECM1-dependent reaction chain may drive further advanced damages in the interaction between ECM1 and other ECM components, ultimately causing the clinicopathology in LiP and LS. Further fine epitope mapping within ECM1 now warrants to identify the pathogenic specificity and/or concealed region(s) for binding of in vivo ECM1 with candidate partners in human skin. Likewise, whether the development of multiple antigenic targets within ECM1 has any pathogenic significance for LS or whether it merely 


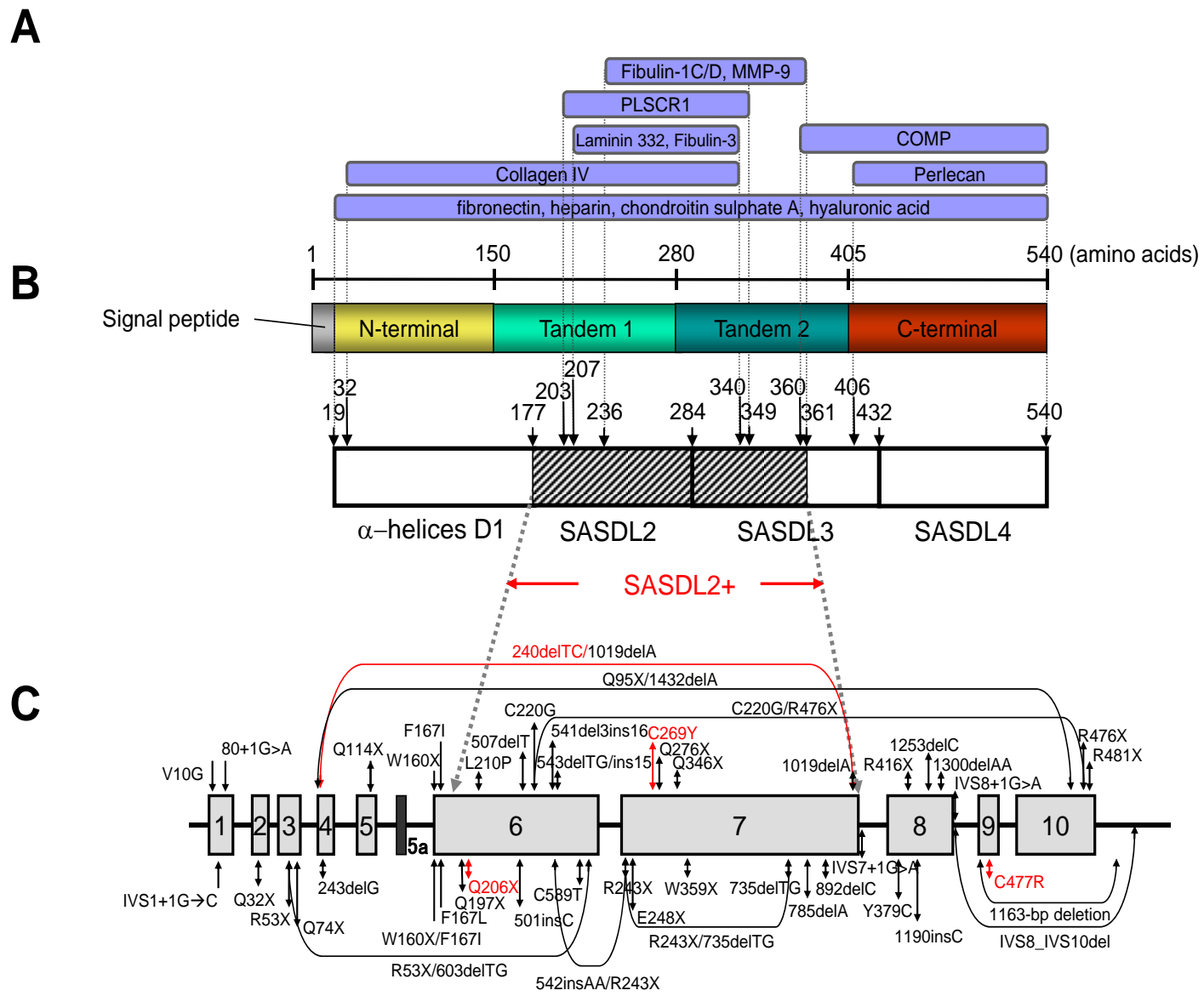

Fig. (2). Summary of the gene and domain organization of the human ECM1 and its binding partners. (A) Site-specific binding of ECM1a protein to different structural and ECM molecules in the skin. A series of in vitro and in vivo binding studies have revealed the biological interaction of ECM1 with the following proteins and polysaccharides at different binding sites; perlecan (406-540 aa of ECM1a) [11], fibulin-1C/1D and MMP-9 (236-361 aa) [70,71], type IV collagen (32-340 aa) [70], laminin 332 and fibulin-3 (207-340 aa) [14,70], PLSCR1 (203-349 aa) [14,73], and COMP (360-540 aa) [74]. The binding of the full-length ECM1a with fibronectin, heparin, chondroitin sulphate A, and hyaluronic acid has also been demonstrated [70], but their exact binding sites within ECM1a has yet to be characterized. ECM1a is capable of enhancing the binding of type IV collagen and laminin 332 [70]. (B) A predicted secondary structure and its corresponding domains of ECM1 a protein. The full-length ECM1a contains a 19-amino acid residue signal peptide and the following four distinct domains; an N-terminal cysteine-free domain, two tandem repeat domains, and a C-terminal domain. The latter three domains contain the characteristic cysteine arrangement CC-(X7-10)-C patterns [6,7], typically observed in the albumin protein family members. This pattern generates double-loop structures that are involved in the protein/protein interactions. The first domain exists of $\alpha$-helices $(\alpha \mathrm{D} 1)$, and the remaining three domains are comparable topologically with the subdomain of the third serum albumin domain, named SASDL2, 3 and 4 [14]. The amino acid numbers corresponding with a mature ECM1a precursor protein were indicated. The SASDL2+ region was used to screen a foreskin cDNA library by $\mathrm{Y} 2 \mathrm{H}$ and instrumental in the identification of fibulin-3, laminin 332, and PLSCR1 as putative ECM1 binders [14,73]. (C) Schematic representation of ECM1 gene structure and mutations in LiP patients. ECM1 gene consists of 10 exons (boxes) and alternative introns (horizontal lines). All the pathogenic ECM1 mutations thus far reported were depicted; previously reported mutations were indicated in black [27], whereas four novel mutations were in red [37-41]. The homozygous mutations were indicated as double arrows. Note that more than a half of all nonsense and flame-shift mutations are located within exon 6 and alternatively spliced exon 7.

represents a secondary phenomenon occurring within the setting of more severe and chronic disease need to be clarified [21].

\section{INFLAMMATORY BOWEL DISEASES AND ECM1}

Substantial advances using epidemiological twin and linkage analysis have been achieved in defining the genetic architecture of inflammatory bowel diseases (IBDs). To date, roughly 60 definite susceptibility genes and loci have been identified in IBDs [87]. Ulcerative colitis (UC; MIM 191390) is one of two major IBDs, characterized by chronic relapsing and remitting inflammatory conditions affecting the colon, invariably with rectum. Normally, inflammation is restricted to the mucosal epithelia, thus establishing a current working hypothesis that the disease pathogenesis is a defective mucosal barrier and dysregulated inflammatory response to the intestinal epithelium [88]. 
Recently, hypothesis-free genome-wide scan for nonsynonymous single nucleotide polymorphisms (SNPs) has yielded the strong association with UC at two different SNPs (rs3737240 and rs13294) in the ECM1 gene [89]. This locus, spanning 290-kb, also contains MRPS21, PRPF3, and TARS2, those of which are mitochondrial and ribonucleoprotein family members. Interestingly, the ECM1 genetic variants have recently been re-screened with the same cohort for one the other major IBD, e.g. Crohn's disease (CD; MIM26600), but there were no significant association with reliable statistical power [90], implying that ECM1 gene confers a susceptibility locus specific for UC. The association of ECM1 with UC was confirmed in the Dutch population [91]. In contrast, ECM1 rs 13294 was not associated with either $\mathrm{CD}$ or UC in Eastern European patients [92]. These evidences may raise the question why LiP and LS, genetic and autoimmune impairment conditions of ECM1 function, respectively, do not consistently exhibit any of intestinal manifestations, and if any, whether it is simply underrecognized or an occult manifestation. Limited case reports for intestinal involvement in $\mathrm{LiP}$ are only available [93].

Nevertheless, ECM1 is a plausible pathogenic candidate for UC; it is ubiquitously expressed throughout the intestine [7], and represents structural integrity and gatekeeping action of transmembrane permeability in the mucosal epithelia. It is therefore possible that ECM1 may be part of the key molecular cascade for the structural/immunological breakdown of mucosal barrier function, thereby allowing an increased antigenic load to trigger a disease-specific intestinal autoimmunity in UC [94,95]. Furthermore, rs 3737240 (exon 6) and rs 13294 (exon 8) encode the amino acid substitutions of $\mathrm{T} 130 \mathrm{M}$ and $\mathrm{S} 290 \mathrm{G}$. Thr130 resides within the binding domain for type IV collagen [70] and is conserved in primates, whereas Ser290 is not. Therefore, it is tempting to speculate that rs37372240 would be rather a pathogenic SNP and may affect the interaction of ECM1 with collagens (e.g. type IV collagen) resulting in excessive collagen production, which is deposited under the membrane giving the histological appearance of a subepithelial collagen band, typically for collagenous colitis [96].

\section{Animal Models for Unraveling In Vivo ECM1 Function}

\section{Ecm1 Knockout Animals}

Among a number of animal models recapitulating features of inherited or acquired autoimmune disorders, mice can be a preferable platform to understand the detailed and/or concealed pathomechanistic insight of the disease. However, mice homozygous for the ECM1 null-mutations, reflecting the pathogenic nature of LiP, are not viable and Ecml-deficient embryos die during pre-implantation development (< day 3.5 postcoitus, E3.5) following a conventional knockout targeting strategy for Ecml. At that stage, the provisional conclusion that ECM1 is indispensable for the early embryonic development has been made [97].

As an alternative approach, a freshwater fish zebrafish (Dario rerio) has recently been utilized to establish a novel animal model for LiP [98]. There are several characteristic advantages that favor choosing this small freshwater fish [99]; it has a rapid maturation and development of organs, as well as skin compartments. Fully developed adult zebrafish skin composes of stratified (multi-layered) epidermis and the underlying collagenous stroma, separated by hemidesmosomal structures in basement membrane zone, those seen in human skin. Interestingly, ecml-knockout zebrafish normally survive and phenotypically reveals altered contour of the skin surface with micropapules and loss of microridges [98]. Microscopically, the mutant zebrafish skin reveals apparent reduplication of basement membrane and pinocytotic vesicle formation in the periphery of dermal fibroblasts, findings seen in LiP skin. Although the identified zebrafish ECM1 protein has $\sim 45 \%$ homology to the equivalent human protein $[100,101]$, the results from rescue transgene experiments using human ECM1a cDNA for the knockdown phenotype suggest accuracy of the ECM1 orthologue in zebrafish [98]. However, the study limitation using zebrafish in skin research includes lack of epidermal differentiation molecules, such as filaggrin, involcurin, trichohyaline genes (the latest zebrafish genome in NCBI database), for which the zebrafish skin do not undergo terminal differentiation, and lower genetic similarity to human $(\sim 56 \%)$ [100,101]. These observations may be a common inevitable difficulty in establishing the overall skin features of $\mathrm{LiP}$ in in-water animals.

In 2010, Li et al. have first demonstrated the ECM1 knockdown in mice by deleting exons 2-11 of the mouse Ecml gene [20]. Since the mice die around 6-8 week ages with uncharacterized autoinflammatory condition, they next generated chimeric mice transplanted with bone marrow cells from Ecml-deficient mice. The most striking observation in the chimeric mice for Ecml was significant attenuation of ovalbumin-induced airway allergic response, a histology showing fewer infiltration of eosinophils, lymphocytes, and macrophages in the bronchoalveolar lavage. Compared with wild-type mice, the activated CD4+Th2 cells of Ecm 1 chimeric mice, but not other T cells including Th1, Th9, Th17, CD8+T cells, and inducible regulatory $\mathrm{T}$ cells (Tregs), were specifically retained in the peripheral lymphoid organs, and did not migrate into the inflammatory sites. Functional assays for several $\mathrm{T}$ cell lineages from Ecml knockout mice exhibited no substantial differences in the proliferation activity, cytokine/chemokine profiles, and polarization of their differentiation, suggesting the direct action of ECM1 in Th2 cell emigration from lymph nodes into the blood [20]. Thus, Li and coworkers discovered a novel role for ECM1 in controlling Th2 cell trafficking during an allergic immune response.

\section{ECM1 Overexpression in Mice Skin}

Considerable progress to address the in vivo ECM1 function has been evolved during the last half decade. Preliminary implication draws functional importance of ECM1 in epidermal differentiation, because the human ECM1 gene locates within a region on chromosome 1q21.2 centromeric to a gene cluster of the epidermal differentiation complex $[7,8,13,102]$. However, in vitro experiments using ECM1a/c-deficient (mutations outside exon 7) and ECM1bdeficient (mutations within exon 7) cultured keratinocytes from LiP patients showed no significant differences in the expression of early and late epidermal differentiation markers, keratin 10 and involucrin, respectively, compared 
(a)

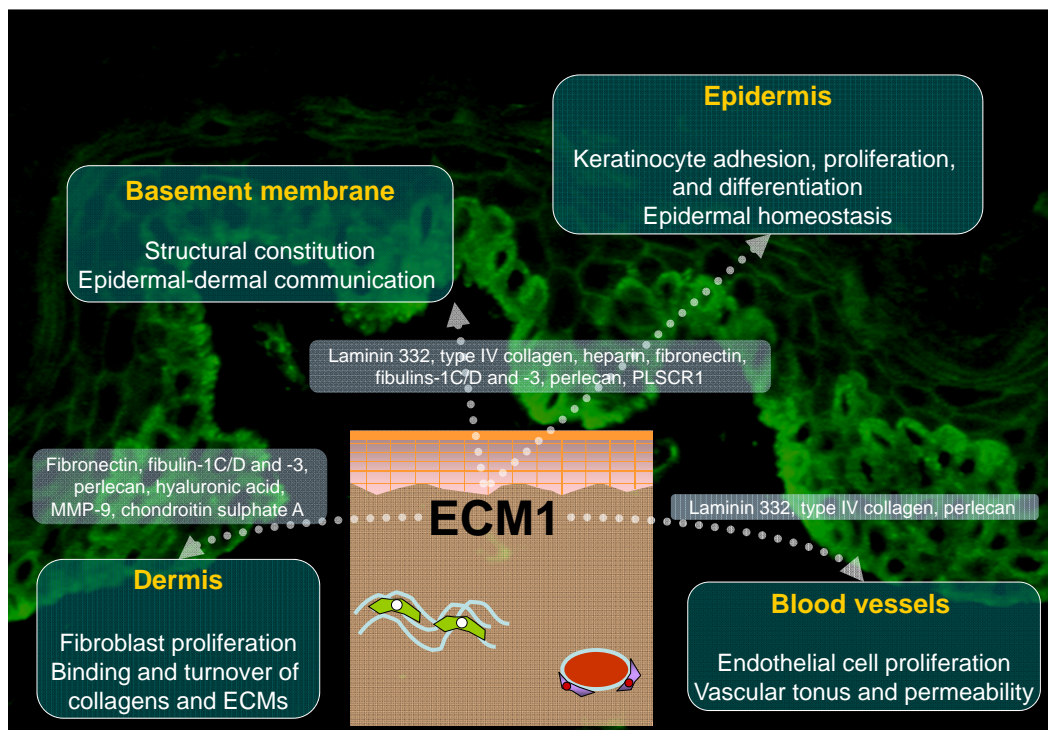

(b)

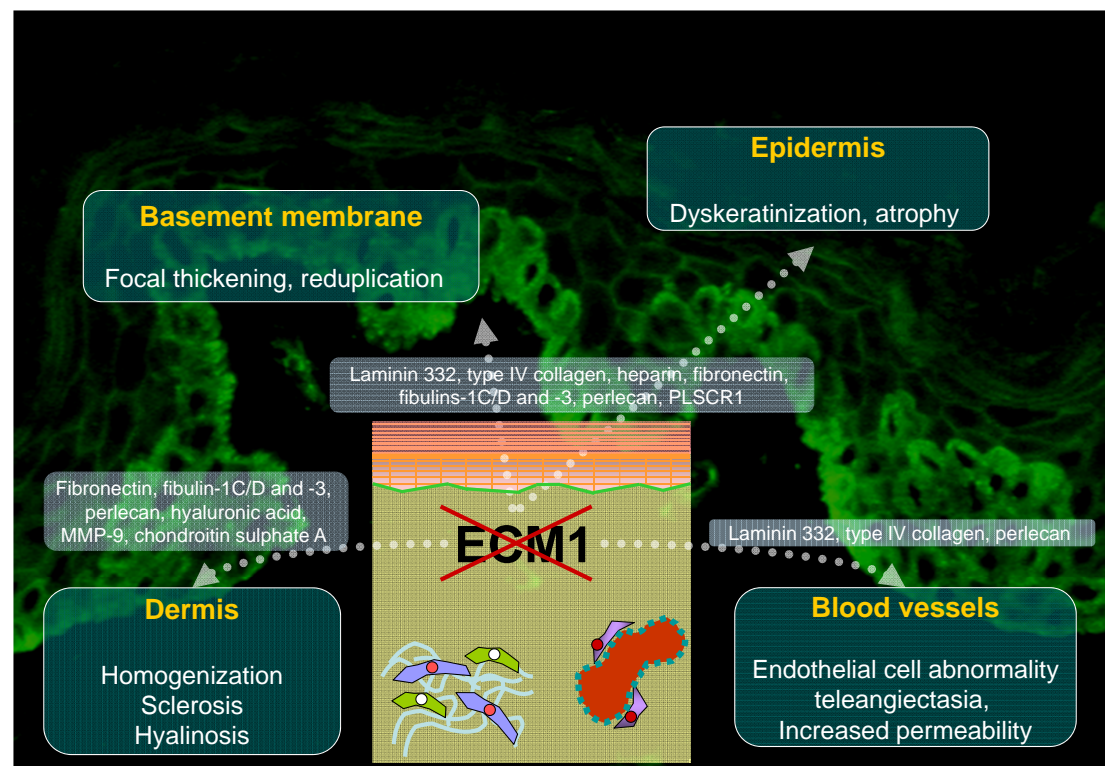

Fig. (3). In vivo ECM1 function and its multifocal assembly in the skin structural and ECM molecules. (A) In human skin, ECM1a is expressed in the epidermal basal layer, dermal blood vessels, the outer root sheath of hair follicles, sebaceous lobules, and sweat gland epithelia, whereas ECM1b was in the suprabasal layers of epidermis [10,11,13]. ECM1 binds to a variety of structural and ECM molecules (gray boxes), forming the stratified epidermis, hemidesmosome, and dermal components in the skin. Most of these molecules are secreted by keratinocytes and fibroblasts, as well as endothelial cells. Laminin 332, fibulin-1, and type IV collagen specifically localize in the basement membrane and dermal blood vessel walls. Major interstitial dermal proteins and polysaccharides contain fibronectin, chondroitin sulphate A, and hyaluronic acid, which bind to ECM1 with different affinities [70]. MMP-9, a proteolytic enzyme for type IV collagen, is capable of binding to ECM1 directly [71], although this specific binding down-regulates the enzymatic activity [152]. ECM1 can act as a "biological glue" in the whole basic framework and physical flexibility in human skin. Background pictures were the immuno-labeling with rabbit antiECM1 antibody [19] in human skin section; positive signals (green) were seen in the cytoplasm of the lower epidermal keratinocytes and dermal blood vessel walls, as well as along with basement membrane zone. PLSC1, phospholipid sclamblase 1; MMP-9, matrix metalloproteinase-9. Impairment of ECM1 function, which caused by genetic ablation (LiP) or autoimmunity (LS), may collapse the multiple assembly with the surrounding skin structural and interstitial molecules, resulting in the clinicopathology characteristics for LiP and LS; hyperkeratosis and atrophy of the epidermis, disruption and duplication of the basement membrane, excess deposition of type IV collagen, perlecan, laminins, and extracellular matrixes around the thickening blood vessel walls with telangiectasia and hyaline changes $[42,43,64,85,86]$. 
with normal human keratinocytes [103]. This observation was further verified with immunolabelling of LiP skin. More surprisingly, mice overexpressing ECM1a at the basal (keratin 14 promoter-driven) and suprabasal layers (involucrin promoter-driven) have demonstrated no morphological and histological changes in the skin, comparable with those of wild type mice [103]. These data indicates that in vivo ECM1 function can be dispensable or otherwise at least compensable for early and terminal differentiation of keratinocytes in a steady-state condition. This notion provides the clinical perspective that warty keratotic appearance of the LiP lesional skin is more unlikely to be a direct consequence of deficient ECM1 function, but may result from chronic exposure with extrinsic factors, such as mechanical stress, temperature, dry, or UV [10,26,103].

\section{Passive Transfer of ECM1 Antibodies in Mice}

To elucidate the pathogenic importance of serum antiECM1 autoantibody in LS, a passive transfer experiment of affinity-purified IgG from LS patients has been challenged to the mice ear skin [21]. This approach reproduced limited features of the clinicopathology seen in LS; the injected skin sites showed marked erythematous swelling with telagiectasie. The pathology of the injected skin sites displayed moderate inflammatory cell infiltration, dilated blood vessels and interstitial edema in the dermis, all of which are compatible with the early skin pathology seen in LS. These changes are anti-ECM1 antibody specific, because i) control human $\operatorname{IgG}$ injection did not show any skin changes, ii) the skin sites injected with affinity-purified LS IgG revealed $\operatorname{IgG}$ deposition in the lower epidermis (intracellular) and surrounding dilated dermal blood vessels, being similar to those found in ECM1 immuno-labeling of normal human skin or mice skin immunostained with antiECM1 rabbit polyclonal antibody [19,21]. Thus, LS IgG is capable of binding with in vivo native ECM1, and also inducing some of LS skin pathology. Despite these specific immunoreactions, the injected skin sites showed no evidence of hyaline and scarring changes, typical skin pathology in established LS [42,43].

A passive transfer experiment failed to recapitulate the complete pathological features of LS skin, but instead, an extrapolation simply from these results provides the underlying pathomechanism of the disease; first, much more prolonged inflammation caused by the anti-ECM1 antibody coordinate with T cell-mediated immune reaction [104-106] - might be needed for establishing the LS skin. Another persuasive evidence is the increased incidence of peri-stoma LS lesions in patients who received urostomy or colostomy [107]. This clinical observation suggests a possible combined role for constitutive urine or stool contact, local skin occlusion, infection (i.e. Gram-negative microorganisms), and perhaps moisturization, a condition akin to the anogenital skin. However, the functional impairment of in vivo ECM1 may not be responsible for the lesional predilection, because ECM1-deficient genodermatosis LiP shows neither a predilection for anogenital skin nor the potential for squamous cell carcinogenesis. Together, a series of current experimental and clinical studies for genital LS may thus propose that a combination of intrinsic and extrinsic factors to the local skin is essential for the development of the characteristic LS skin. From the clinical perspective, further animal studies injecting anti-ECM1 antibody to the anogenital area needs to be appraisal.

\section{ECM1 Expression in Different Cell Sources}

\section{Cell Lines and Normal Cells}

In human, various types of normal and malignant cell lineages express at least any of the three ECM1 variants, ECM1 a-c. As listed below, in vitro and histochemical studies have revealed the expression of ECM1 transcription and/or protein in keratinocytes $[7,13]$, dermal fibroblasts and papilla cells $[11,18,108]$, vascular endothelial cells, squamous carcinoma A431 cells, fibrosarcoma HT1080 cells [11], osteosarcoma Saos2 cells [7], cholangiocarcinoma cells [109], and hepatocellular carcinoma cells [110], bonemetastatized lung adenocarcinoma SPC-A-1BM cells [111], HaCaT keratinocytes [73], mammary epithelial cells, estrogen receptor-positive breast cancer MCF-7 cells, estrogen receptor-negative bone-metastatized breast cancer MDA-MB-231 cells/-435 cells, Hs578T cells, and LCC-15 cells [112-114], embryonic kidney 293 cells [115], chondrogenic ATDC-5 cells [116], and pancreatic cancer SW1990 cells and Capan-2 cells [117].

Again, these evidences suggest that ECM1 has an essential role in the vast majority of cell sources, as well as development and maintenance of malignant potential. As a preliminary data, the amount of ECM1c transcript was estimated to be $\sim 15 \%$ of the total ECM1 mRNA in A431 cells and HT1080 cells [11], implying the possibility of an ECM1 isoform-specific regulation in each cell lineage. However, antibodies discriminating these three ECM1 isoforms are currently not available, and also it is not evident that the detectable transcription rates indeed reflect the protein expression levels of the corresponding ECM1 isoforms. Investigation of the isoform-specific expression of ECM1 may be crucial for identifying the detailed characteristics of malignant potential and local behavior in each cancer.

\section{Lymphocyte Biology and ECMI}

DNA microarray assays have recently disclosed the expression of ECM1 in mouse hematopoietic cells, particularly in $\mathrm{T}$ cells $[118,119]$. Of note, the ECM1 transcription levels considerably differ in differentiation- and cell lineage-dependent manners; it was much higher in CD4+ helper $\mathrm{T}$ cells and CD4+CD25+T cells (Tregs) than CD8+ cytotoxic $\mathrm{T}$ cells and CD3-negative naïve $\mathrm{T}$ cells, but their expression rates in the equivalent cell sources were unchanged between thymus, spleen, and peripheral lymph nodes. Among CD4+ helper $\mathrm{T}$ cell phenotypes, ECM1 expression was almost restricted to the Th2 cells [20], implicating the possible association between ECM1 and allergic reaction. This was supported by the finding that chimeric $\mathrm{BALB} / \mathrm{c}$ mice transplanted with Ecml-deficient bone marrow cells showed decrease of inflammatory response in experimentally induced airway allergy [20] and depletion of $\mathrm{CD} 25+\mathrm{T}$ cells in wild type C57BL/6 mice dramatically increased the priming and expansion of antigenspecific T-cell precursors via gamma-interferon induction in allergic contact skin hypersensitivity $[119,120]$. In Th2 cells, mRNA expression and protein secretion of ECM1 were detectable at 3 days after antigen-dependent engagement of 
T cell receptor. Subsequently ECM1 binds with IL-2 receptor $\beta$-subunit (CD122), but neither with CD25 nor CD132, to inhibit the phosphorylation and activation of the downstream signaling molecules, such as STAT5, KLF2, and S1P1 [20], finally resulting in the down regulation of Th2 cell trafficking to the inflammatory sites. On the other hand, both freshly isolated and activated CD4+CD25+Tregs have been confirmed to express higher levels of ECM1 transcript [118]. CD4+CD25+Tregs are well known to regulate innate and adaptive immune responses, an effective tumor immunity to autologous tumor cells, and a potent antiinflammatory capacity in autoimmune and chronic inflammatory diseases, such as autoimmune encephalitis, diabetes, thyroiditis, IBDs, and contact skin hypersensitivity [120-125]. Naturally occurring Tregs, the other Treg phenotype, which comprise up to $5 \%$ of the peripheral CD4+T cell pool, have also shown to express ECM1 [121]. More critically, the ECM1 transcription was significantly increased in naïve $\mathrm{T}$ cells by transient transduction of Forkhead box P3 (Foxp3), a transcription factor that acts as a master control molecule for the development and function of CD4+CD25+Tregs in the thymus and periphery [126].

Immunohistologically, the percentage of FoxP3+lymphocytes was increased in the lesional skin of female genital LS, compared with those of male penile LS and normal control [105]. Although the precise function of infiltrating Tregs in the lesional LS skin remains undefined, the local autoimmune reaction is initiated by decrease or absence of acquired immune tolerance organized by Tregs. This concept is supported by evidence series that the frequency of locally infiltrating Tregs was decreased in autoimmune blistering and sclerotic diseases, such as bullous pemphigoid, scleroderma, and morphea [127,128]. To unravel, the exact pathogenic relationship between Tregs and humoral autoimmunity to ECM1 in LS, passive transfer experiments of anti-ECM1 antibody into the Treg-depleted mice or under conditional Treg-suppression may be of necessary.

\section{ECM1 EXPRESSION IN CELL SIGNALING AND CANCER BIOLOGY}

A series of recent evidence has emerged the direct link of abnormal ECM1 expression with aspects of malignant potential. Most of these comprises the overexpression properties of ECM1 in a wide variety of malignant epithelial and internal tumors, including breast carcinoma, esophageal squamous carcinoma, and, gastric, colorectal, pancreatic, hepatic carcinomas $[17,109,110,129]$. Elevated levels of ECM1 transcript(s) and protein have also been demonstrated in malignant thyroid neoplasms [130], and can clinically represent diagnostic and prognostic significance in individual cases with hepatic and breast cancers [131,132]. This is in line with aberrant ECM1 expression in the cell lines originating from equivalent malignant tissues and organs. ECM1 has been also shown to have an important role in the growth, metastasis and angiogenetic stromal response of laryngeal carcinoma [133]. In vitro studies using an established cholangiocarcinoma cell line has shown the increase of ECM1 expression and NF-kB/Akt cascade activity [109]. ECM1 expression is influenced by the Wnt $\beta$ catenin signal transduction pathway, dysregulation of which has been implicated in the tumor pathogenesis in mammary glands, colon and skin [113]. ECM1 and its downstream accessory signals may therefore be involved in the important interaction between tumors and local microenvironment in different tissues. Indeed, ECM1 has recently been shown to be overexpressed in a human tumor metastasis model, further emphasizing a key role for ECM1 in epithelialstromal interactions [134]. Upon the recent wide-genome screening, however, ECM1 gene loci have yet to be formally associated with secondary developed colorectal cancer in IBDs, as well as any types of primary internal cancers [89]. In addition, LiP patients (an ECM1-deficient human model) have no predilection for skin and internal malignancies. The lack of association between ECM1 and genetic susceptibility for tumor development has yet to be fully characterized.

\section{ECM1 FUNCTION IN SKIN AGEING}

Skin ageing is an inevitable progressive deterioration of various physiological functions, which are principally divided into intrinsic (chronological) and extrinsic (photo) ageing, although the latter is mostly superimposed on the intrinsic mode [135]. The intrinsic ageing is slowly progressive occurring in the entire body skin, a morphological feature showing fine shallow wrinkles, lack of elasticity and tensile strength, and hypochromic surface. The skin pathology shows thinner (atrophic) epidermis with degeneration of the underlying connective tissues. These changes are substantiated by reduced expression of extracellular matrix molecules, such as interstitial collagens, elastin, fibulins, and glycosaminoglycans, further accelerated by enhanced release of matrix-degrading metalloproteases and the resultant decrease of ECM and elastin, fibrillin-1 [136-139]. In contrast, the photoageing of skin shows coarse deep wrinkles with yellow-brownish surface, abrupt keratinization and pigmentation, and telangiectasia [135]. Pathologically it shows irregularly thickened (acanthotic) and atrophic epidermis with loss of keratinocyte polarity and dysregulation of melanocyte density, and more significantly, dermal elastolysis caused by repeated degeneration and production of collagen/elastic fibers, and excess deposition of glycosaminoglycans [136,140-142]. Thus, the skin ageing pathology is closely associated with an imbalance of the biological network of ECMs and collagens.

ECM1 expression is downregulated in the intrinsically aged skin protected from chronic UV exposure, but inversely increased by acute (transient) and chronic UV exposure (photoageing) [10]. The bipolar responses of ECM1 are followed by up-/down-regulation cascades of its binding partners, including MMPs, type IV collagen, laminin 332, fibronectin, perlecan, and transforming growth factor (TGF)$\beta$, finally affecting the biological activity of dermal fibroblasts, and recomposition of the structural proteins and surrounding ECM molecules [10,14,70,85,86]. Combining with the clinical observation that sun-exposed LiP skin tends to have severe scarring and photo-aged appearance compared with non-exposed skin [143], ECM1 may play a photoprotective role in human skin. However, the expression levels of TGF- $\beta$ mRNA and protein did not significantly differ between female genital (non-UV exposed) LS and normal subjects $[144,145]$, suggesting that differences of the disease stage, duration of the disease, and ongoing treatments in each patient might affect the expression of fibrogenic and collagenogenic molecules. 
Cigarette smoking is a deleterious extrinsic factor for skin ageing [146]. Not only epidemiological studies using large cohorts or twins [147,148], but also in vitro studies using cultured mesenchymal cell sources, dermal fibroblasts and osteoblasts, have demonstrated that cigarette smoke extracts and/or nicotine alter the baseline production of collagens, fibronectin, and elastin, and also increase MMPs, which accelerates the degrading and aberrant deposit of collagens and ECMs [146,149]. Moreover, chronic nicotine exposure decreases the binding activity of transcription factor AP1 with its binding sequences [150], which may cause the down-regulation of AP1-dependent gene expression, including ECM1; human, mouse, and rat ECM1 gene promoter regions contain one or two functional binding sites for AP1 [9]. An imbalance between biosynthesis and breakdown in dermal connective tissue metabolism, as well as direct transcriptional regulation of ECM1 gene, may thus participate in the smoking-induced skin ageing.

\section{CONCLUSION}

Considerable progress in animal model studies for determining the in vivo ECM1 function and new insights of this molecule into the particular $\mathrm{T}$ cell subsets, CD4+CD25+Tregs and Th2 cells, and genetic susceptibility of ulcerative colitis, have been made the last decade. For functional ECM1 impairment, however, genetic ablation and passive transfer of the specific antibody in mice have not fully explained the pathophysiological characteristics in LiP and LS. An extrapolation simply from the clinical observation that LiP patients are viable without a predilection of skin and internal malignancies, ECM1 can be dispensable or otherwise, at least compensable for the development of any types of organs, including skin. Likewise, ECM1 may not be responsible for a higher complication of squamous cell carcinomas in the longstanding LS skin. Nevertheless, multi-angle researches for ECM1 binding partners and associated signaling molecules reinforce the potential importance of ECM1 in the complex skin organization and homeostasis, and more surprisingly, the lung regeneration in post-pneumonectomy mice [151] and its physiological role in ureteric bud branching and nephron development (C. Mendelsohn, unpublished results) Further unraveling the pleiotropic action of ECM1 in the cell and tissue biology needs to be activated.

\section{CONFLICT OF INTEREST}

The authors confirm that this article content has no conflict of interest.

\section{ACKNOWLEDGEMENTS}

Declared none.

\section{REFERENCES}

[1] Pulkkinen L, Ringpfeil F, Uitto J. Progress in heritable skin diseases: Molecular bases and clinical implications. J Am Acad Dermatol 2002; 47: 91-104.

[2] Feramisco JD, Sadreyev RI, Murray ML, et al. Phenotypic and genotypic analyses of genetic skin disease through the Online Mendelian Inheritance in Man (OMIM) database. J Invest Dermatol 2009; 129: 2628-38.

[3] Uitto J. Progress in heritable skin diseases: Translational implications of mutation analysis and prospect of molecular therapies. Acta Derm Venereol 2009; 89: 228-35.
[4] Leech SN, Moss C. A current and online genodermatosis database. Br J Dermatol 2007; 156: 1115-48.

[5] Mathieu E, Meheus L, Raymackers J, Merregaert J. Characterization of the osteogenic stromal cell line MN7: identification of secreted MN7 proteins using two-dimensional polyacrylamide gel electrophoresis, western blotting, and microsequencing. J Bone Miner Res 1994; 9: 903-13.

[6] Bhalerao J, Tylzanowski P, Filie JD, et al. Molecular cloning, characterization, and genetic mapping of the cDNA coding for a novel secretory protein of mouse. Demonstration of alternative splicing in skin and cartilage. J Biol Chem 1995; 270: 16385-94.

[7] Smits P, Ni J, Feng P, et al. The human extracellular matrix gene 1 (ECM1): genomic structure, cDNA cloning, expression pattern and chromosomal localization. Genomics 1997: 45: 487-95.

[8] Johnson MR, Wilkin DJ, Vos HL, et al. Characterization of the human extracellular matrix protein 1 gene on chromosome 1q21. Matrix Biol 1997: 16: 289-92.

[9] Smits P, Bhalerao J, Merregaert J. Molecular cloning and characterization of the mouse $\mathrm{Ecm} 1$ gene and its 5 ' regulatory sequences. Gene 1999; 226: 253-61.

[10] Sander C, Sercu S, Ziemer M, et al. Expression of extracellular matrix protein 1 (ECM1) in human skin is decreased by age and increased upon ultraviolet exposure. Br J Dermatol 2006; 154: 21824.

[11] Mongiat $\mathrm{M}, \mathrm{Fu} \mathrm{J}$, Oldershaw $\mathrm{R}$, et al. Perlecan protein core interacts with extracellular matrix protein 1 (ECM1), a glycoprotein involved in bone formation and angiogenesis. J Biol Chem 2003; 278: 17491-9.

[12] Horev H, Potikha T, Ayalon V, et al. A novel splice-site mutation in ECM-1 gene in a consanguineous family with lipoid proteinosis. Exp Dermatol 2005: 14: 891-7.

[13] Smits P, Poumay Y, Karperien M, et al. Differentiation-dependent alternative splicing and expression of the extracellular matrix protein 1 gene in human keratinocytes. J Invest Dermatol 2000; 114: 718-24.

[14] Sercu S, Lambeir AM, Steenackers E, et al. ECM1 interacts with fibulin-3 and the beta 3 chain of laminin 332 through its serum albumin subdomain-like 2 domain. Matrix Biol 2009; 28: 160-9.

[15] Deckers M, Smits P, Karperien M, et al. Recombinant human extracellular matrix protein 1 inhibits alkaline phosphatase activity and mineralization of mouse embryonic metatarsals in vitro. Bone 2001; 28: 14-20.

[16] Han Z, Ni J, Smits P, et al. Extracellular matrix protein 1 (ECM1) has angiogenic properties and is expressed by breast tumor cells. FASEB J 2001; 15: 988-94.

[17] Sercu S, Zhang L, Merregaert J. The extracellular matrix protein 1: its molecular interaction and implication in tumor progression. Cancer Invest 2008; 26: 375-84.

[18] Hamada T, McLean WHI, Ramsay M, et al. Lipoid proteinosis maps to 1q21 and is caused by mutations in the extracellular matrix protein 1 gene (ECM1). Hum Mol Genet 2002: 11: 833-40.

[19] Oyama N, Chan I, Neill SM, et al. Autoantibodies to extracellular matrix protein 1 in lichen sclerosus. Lancet 2003; 362: 118-23.

[20] Li Z, Zhang Y, Liu Z, et al. ECM1 controls T(H)2 cell egress from lymph nodes through re-expression of S1P(1). Nat Immunol 2011; 12: 178-85.

[21] Oyama N, Chan I, Neill SM, et al. Development of antigen-specific ELISA for circulating autoantibodies to extracellular matrix protein 1 in lichen sclerosus. J Clin Invest 2004; 113: 1550-9.

[22] Sercu S, Oyama N, Merregaert J. Importance of extracellular matrix protein 1 (ECM1) in maintaining the functional integrity of the human skin. Open Dermatol J 2009; 3: 44-51.

[23] Urbach E, Wiethe C. Lipoidosis cutis et mucosae. Virchows Arch A Pathol Pathol Anat 1929: 273: 285-319

[24] Hofer P. Urbach-Wiethe disease (lipoglycoproteinosis; lipoid proteinosis; hyalinosis cutis et mucosae). A review. Acta Derm Venereol Suppl (Stockh) 1973; 53: 1-52.

[25] Hamada T. Lipoid proteinosis. Clin Exp Dermatol 2002; 27: 624-9.

[26] Chan I, El-Zurghany A, Zendah B, et al. Molecular basis of lipoid proteinosis in a Libyan family. Clin Exp Dermatol 2003; 28: 545-8.

[27] Chan I, Liu L, Hamada T, et al. The molecular basis of lipoid proteinosis: mutations in extracellular matrix protein 1. Exp Dermatol 2007; 16: 881-90.

[28] Al-Faky Y, Bosley T, Al-Turki T, et al. Prominent corneal nerves: a sign of lipoid proteinosis. Br J Ophthalmol 2012; 96: 935-40. 
[29] Teive HA, Pereira ER, Zavala JA, et al. Generalized dystonic and striatal calcifications with lipoid proteinosis. Neurology 2004; 63: 2168-9.

[30] Wiest G, Lehner-Baumgartner E, Baumgartner C. Panic attacks in an individual with bilateral selective lesions of the amygdala. Arch Neurol 2006: 63: 1798-801.

[31] Hurlemann R, Wagner M, Hawellek B, et al. Amygdala control of emotion-induced forgetting and remembering: evidence from Urbach-Wiethe disease. Neuropsychologia 2007; 45: 877-84.

[32] Siebert M, Markowitsch HJ, Bartel P. Amygdala, affect and cognition: evidence from 10 patients with Urbach-Wiethe disease. Brain 2003: 126: 2627-37.

[33] Claeys K, Claes L, Van Goethem J, et al. Epilepsy and migraine in a patient with Urbach-Wiethe disease. Seizure 2007; 16: 465-8.

[34] Thorton H, Nel D, Thorton D, et al. The neurospychiatry and neuropsychology of lipoid proteinosis. J Neuropsychiatry Clin Neurosci 2008; 20: 86-92.

[35] Gündüz O, Sahiner N, Atasoy P, et al. Acitretin treatment for lipoid proteinosis. Case Rep Dermatol Med 2012; 23(4): 482-3.

[36] Akoglu G, Karaduman A, Ergin S, et al. Clinical and histopathological response to acitretin therapy in lipoid proteinosis. J Dermatol Treat 2011; 22: 178-83.

[37] Horev L, Wollina DU, Potikha T, et al. Lipoid proteinosis: identification of two novel mutations in the human ECM-1 gene and lack of genotype-phenotype correlation. Acta Derm Venereol 2009; 89: 528-9.

[38] Nasir M, Latif A, Ajmal M, et al. Molecular analysis of lipoid proteinosis: identification of a novel nonsense mutation in the ECM1 gene in a Pakistani family. Diagn Pathol 2011; 6: 69.

[39] Salih MA, Abu-Amero KK, Alrasheed S, et al. Molecular and neurological characterizations of three Saudi families with lipoid proteinosis. BMC Med Genet 2011; 12: 31.

[40] Izadi F, Mahjoubi F, Farhadi M, et al. A novel missense mutation in exon 7 of the ECM1 gene in an Iranian lipoid proteinosis patient. Genet Mol Res 2012; 11: 3955-60.

[41] Liu W, Xu W, Yang X, Lian S. A novel missense mutation of the ECM1 gene in a Chinese patient with lipoid proteinosis. Clin Exp Dermatol 2011; 37: 28-30.

[42] Powell JJ, Wojnarowska F. Lichen sclerosus. Lancet 1999; 353: 1777-83.

[43] Meffert JJ, Davis BM, Grimwood RE. Lichen sclerosus. J Am Acad Dermatol 1995; 32: 393-416.

[44] Kyriakis KP, Emmanuelides S, Terzoudi S, et al. Gender and age prevalence distributions of morphea en plaque and anogenital lichen sclerosus. J Eur Acad Dermatol Venereol. 2007; 21: 825-6.

[45] Lansdorp CA, van den Hondel KE, Korfage IJ, et al. Quality of life in Dutch women with lichen sclerosus. Br J Dermatol 2012; 168(4): 787-93.

[46] Tasker GL, Wojnarowska F. Lichen sclerosus. Clin Exp Dermatol 2003; 28: 128-33.

[47] Neill SM, Lewis FM, Tatnall FM, Cox NH; British Association of Dermatologists. British Association of Dermatologists' guidelines for the management of lichen sclerosus 2010. Br J Dermatol 2010; 163: 672-82.

[48] Friedrich EG Jr, MacLaren NK. Genetic aspects of vulvar lichen sclerosus. Am J Obstet Gynecol 1984; 150: 161-6.

[49] Powell J, Wojnarowska F, Winsey S, et al. Lichen sclerosus premenarche: autoimmunity and immunogenetics $\mathrm{Br}$ J Dermatol 2000; 142: 481-4.

[50] Meyrick Thomas RH, Ridley CM, et al. Lichen sclerosus et atrophicus and autoimmunity--a study of 350 women. $\mathrm{Br} \mathrm{J}$ Dermatol 1988; 118: 41-6.

[51] Meyrick Thomas RH, Kennedy CT. The development of lichen sclerosus et atrophicus in monozygotic twin girls. Br J Dermatol 1986; 114: 377-9.

[52] Sahn EE, Bluestein EL, Oliva S. Familial lichen sclerosus et atrophicus in childhood. Pediatr Dermatol 1994; 11: 160-3.

[53] Azurdia RM, Luzzi GA, Byren I, et al. Lichen sclerosus in adult men: a study of HLA associations and susceptibility to autoimmune disease. Br J Dermatol 1999; 140: 79-83.

[54] Purcell KG, Spencer LV, Simpson PM, et al. HLA antigens in lichen sclerosus et atrophicus. Arch Dermatol 1990; 126: 1043-5.

[55] Tremaine R, Adam JE, Orizaga M. Morphea coexisting with lichen sclerosus et atrophicus. Int J Dermatol 1990; 29: 486-9.

[56] Wright AJ. Lichen sclerosus thyroid disease. J Reprod Med 1998; 43: 240 .
[57] García-Bravo B, Sánchez-Pedreño P, Rodríguez-Pichardo A Camacho F. Lichen sclerosus et atrophicus. A study of 76 cases and their relation to diabetes. J Am Acad Dermatol 1988; 19: 4825 .

[58] Harrington CI, Dunsmore IR. An investigation into the incidence of auto-immune disorders in patients with lichen sclerosus and atrophicus. Br J Dermatol 1981; 104: 563-6.

[59] Meyrick Thomas RH, Ridley CM, Black MM. The association of lichen sclerosus et atrophicus and autoimmune-related disease in males. Br J Dermatol 1983; 109: 661-4.

[60] Marren P, Dean D, Charnock M, Wojnarowska F. The basement membrane zone in lichen sclerosus: an immunohistochemical study. Br J Dermatol 1997; 136: 508-14.

[61] Baldo M, Bhogal B, Groves RW, et al. Childhood vulval lichen sclerosus: autoimmunity to the basement membrane zone protein BP180 and its relationship to autoimmunity. Clin Exp Dermatol 2010; 35: 543-5.

[62] Irvine HG. Idiopathic atrophy of the skin. JAMA 1913; 61: 396400.

[63] Monteagudo B, Cabanillas M, Bellido D, et al. Lichen sclerosus atrophicus at an insulin injection site: an unusual koebner phenomenon. Actas Dermosifiliogr 2010; 101: 563-5

[64] Kowalewski C, Kozłowska A, Chan I, et al. Three-dimensiona imaging reveals major changes in skin microvasculature in lipoid proteinosis and lichen sclerosus. J Dermatol Sci 2005; 38: 215-24.

[65] Edmonds EV, Oyama N, Chan I, et al. Extracellular matrix protein 1 autoantibodies in male genital lichen sclerosus. Br J Dermatol 2011; 165: 218-9.

[66] Kreuter A, Kryvosheyeva Y, Terras S, et al. Association of autoimmune diseases with lichen sclerosus in 532 male and female patients. Acta Derm Venereol 2013; 93(2): 238-41.

[67] Edmonds EV, Hunt S, Hawkins D, et al. Clinical parameters in male genital lichen sclerosus: a case series of 329 patients. J Eur Acad Dermatol Venereol 2012; 26: 730-7.

[68] Kawakami Y, Oyama N, Hanami Y, et al. A case of lichen sclerosus of the scalp associated with autoantibodies to extracellular matrix protein 1. Arch Dermatol 2009; 145: 1458-60.

[69] Douderova D, Schneider-Yin X, Lautenschlager S, et al. Lichen sclerosus et atrophicus-like skin lesions in a patient carrying a novel hydroxymethylbilane synthase mutation. Blood Cells Mol Dis 2010; 45: 176-9.

[70] Sercu S, Zhang M, Oyama N, et al. Interaction of extracellular matrix protein 1 with extracellular matrix components: ECM1 is a basement membrane protein of the skin. J Invest Dermatol 2008; $128: 1397-408$

[71] Fujimoto N, Terlizzi J, Aho S, et al. Extracellular matrix protein 1 inhibits the activity of matrix metalloproteinase 9 through highaffinity protein/protein interactions. Exp Dermatol 2006; 15: 300-7.

[72] Fujimoto N, Terlizzi J, Brittingham R, et al. Extracellular matrix protein 1 interacts with the domain III of fibulin-1C and 1D variants through its central tandem repeat 2 . Biochem Biophys Res Commun 2005; 333: 1327-33

[73] Merregaert J, Van Langen J, Hansen U, et al. Phospholipid scramblase 1 is secreted by a lipid raft-dependent pathway and interacts with the extracellular matrix protein 1 in the dermal epidermal junction zone of human skin. J Biol Chem 2010; 285: 37823-37.

[74] Kong L, Tian Q, Guo F, et al. Interaction between cartilage oligomeric matrix protein and extracellular matrix protein 1 mediates endochondral bone growth. Matrix Biol 2010; 29: 276-86.

[75] Di Cesare PE, Fang C, Leslie MP, et al. Expression of cartilage oligomeric matrix protein (COMP) by embryonic and adult osteoblasts. J Orthop Res 2000; 18: 713-20.

[76] Hedbom E, Antonsson P, Hjerpe A, et al. Cartilage matrix proteins An acidic oligomeric protein (COMP) detected only in cartilage. J Biol Chem 1992; 267: 6132-6.

[77] Briggs MD, Hoffman SM, King LM, et al. Pseudoachondroplasia and multiple epiphyseal dysplasia due to mutations in the cartilage oligomeric matrix protein gene. Nature 1995; 10: 330-6.

[78] Ettner N, Göhring W, Sasaki T, et al. The N-terminal globular domain of the laminin alphal chain binds to alphalbetal and alpha2beta1 integrins and to the heparan sulfate-containing domains of perlecan. FEBS Lett 1998; 430: 217-21. 
[79] Hopf M, Göhring W, Kohfeldt E, et al. Recombinant domain IV of perlecan binds to nidogens, laminin-nidogen complex, fibronectin, fibulin-2 and heparin. Eur J Biochem 1999; 259: 917-25.

[80] Göhring W, Sasaki T, Heldin CH, Timpl R. Mapping of the binding of platelet-derived growth factor to distinct domains of the basement membrane proteins BM-40 and perlecan and distinction from the BM-40 collagen-binding epitope. Eur J Biochem 1998; 255: 60-6.

[81] Mongiat M, Taylor K, Otto J, et al. The protein core of the proteoglycan perlecan binds specifically to fibroblast growth factor-7. J Biol Chem 2000; 275: 7095-100.

[82] Jiang X, Couchman JR. Perlecan and tumor angiogenesis. J Histochem Cytochem 2003; 51: 1393-410.

[83] Raymond MA, Désormeaux A, Laplante P, et al. Apoptosis of endothelial cells triggers a caspase-dependent anti-apoptotic paracrine loop active on VSMC. FASEB J 2004; 18:705-7.

[84] Chan I. The role of extracellular matrix protein 1 in human skin. Clin Exp Dermatol 2004; 29: 52-6.

[85] Mirancea N, Hausser I, Beck R, et al. Vascular anomalies in lipoid proteinosis (hyalinosis cutis et mucosae): basement membrane components and ultrastructure. J Dermatol Sci 2006; 42: 231-9.

[86] Mirancea N, Hausser I, Metze D, et al. Junctional basement membrane anomalies of skin and mucosa in lipoid proteinosis (hyalinosis cutis et mucosae). J Dermatol Sci 2007; 45: 175-85.

[87] Thompson AI, Lees CW. Genetics of ulcerative colitis. Inflamm Bowel Dis 2011; 17: 831-48.

[88] Xavier RJ, Podolsky DK. Unravelling the pathogenesis of inflammatory bowel disease. Nature 2007; 448: 427-34.

[89] Fisher SA, Tremelling M, Anderson CA, et al. Genetic determinants of ulcerative colitis include the ECM1 locus and five loci implicated in Crohn's disease. Nat Genet 2008; 40: 710-2.

[90] Anderson CA, Massey DC, Barrett JC, et al. Investigation of Crohn's disease risk loci in ulcerative colitis further defines their molecular relationship. Gastroenterology 2009; 136: 523-9.

[91] Festen E, Stokkers P, van Diemen C, et al. Genetic analysis in a Dutch study sample identifies more ulcerative colitis susceptibility loci and shows theri additive role in disease risk. Am $\mathbf{J}$ Gastroenterol 2010; 105: 395-402.

[92] Meggyesi N, Kiss L, Koszarska M, et al. NKX2-3 and IRGM variants are associated with disease susceptibility to IBD in Eastern European patients. World J Gastroenterol 2010; 16: 5233-40.

[93] Caccamo D, Jaen A, Telenta M, et al. Lipoid proteinosis of the small bowel. Arch Pathol Lab Med 1994; 118: 572-4.

[94] Gitter AH, Wullstein F, Fromm M, Schulzke JD. Epithelial barrier defects in ulcerative colitis: characterization and quantification by electrophysiological imaging. Gastroenterology 2001; 121: 1320-8.

[95] Kitajima S, Takuma S, Morimoto M. Changes in colonic mucosal permeability in mouse colitis induced with dextran sulfate sodium. Exp Anim 1999; 48: 137-43.

[96] Pardi DS, Smyrk TC, Tremaine WJ, Sandborn WJ. Microscopic colitis: a review. Am J Gastroenterol 2002; 97: 794-802.

[97] Sercu S. Investigation of the biological role of the extracellular matrix protein 1 in human skin. Ph.D-thesis. Belgium:University of Antwerpen 2007; pp.77-95.

[98] Li Q, Donahue A, Smith S, et al. Zebrafish model of lipoid proteinosis. J Invest Dermatol 2011; 131: S70 (abst).

[99] Li Q, Frank M, Thisse CI, et al. Zebrafish: a model system to study heritable skin diseases. J Invest Dermatol 2011; 131: 565-71.

[100] Barbazuk WB, Korf I, Kadavi C, et al. The syntenic relationship of the zebrafish and human genomes. Genome Res 2000; 10: 1351-8.

[101] Lieschke GJ, Currie PD. Animal models of human disease: zebrafish swim into view. Nat Rev Genet 2007; 8: 353-67.

[102] Mischke D, Korge BP, Marenholz I, et al. Genes encoding structural proteins of epidermal cornification and S100 calciumbinding proteins form a gene complex ("epidermal differentiation complex") on human chromosome 1q21. J Invest Dermatol 1996; 106: 989-92.

[103] Sercu S, Poumay Y, Herphelin F, et al. Functional redundancy of extracellular matrix protein 1 in epidermal differentiation. $\mathrm{Br} \mathrm{J}$ Dermatol 2007; 157: 771-5.

[104] Farrell AM, Dean D, Millard PR, et al. Cytokine alterations in lichen sclerosus: an immunohistochemical study. Br J Dermatol 2006; 155: 931-40.

[105] Terlou A, Santegoets LA, van der Meijden WI, et al. An autoimmune phenotype in vulvar lichen sclerosus and lichen planus: a Th1 response and high levels of microRNA-155. J Invest Dermatol 2012; 132: 658-66.

[106] Gambichler T, Belz D, Terras S, Kreuter A. Humoral and cellmediated autoimmunity in lichen sclerosus. Br J Dermatol 2013 [Epub ahead of print].

[107] Al-Niaimi F, Lyon C. Peristomal lichen sclerosus: The role of occlusion and urine exposure? Br J Dermatol 2012. [Epub ahead of print].

[108] Won C, Kwon O, Kang Y, et al. Comparative secretome analysis of human follicular dermal papilla cells and fibroblasts using shotgun proteomics. BMB Rep 2012; 45: 253-8.

[109] Xiong GP, Zhang JX, Gu SP, Wu YB, Liu JF. Overexpression of ECM1 contributes to migration and invasion in cholangiocarcinoma cell. Neoplasma 2012; 59: 409-15.

[110] Chen H, Jia WD, Li JS, et al. Extracellular matrix protein 1, a novel prognostic factor, is associated with metastatic potential of hepatocellular carcinoma. Med Oncol 2011;28 Suppl 1:S318-25.

[111] Yang S, Dong Q, Yao M, et al. Establishment of an experimental human lung adenocarcinoma cell line SPC-A-1BM with high bone metastases potency by $(99 \mathrm{~m}) \mathrm{Tc}-\mathrm{MDP}$ bone scintigraphy. Nucl Med Biol 2009;36: 313-21.

[112] López-Marure R, Contreras PG, Dillon JS. Effects of dehydroepiandrosterone on proliferation, migration, and death of breast cancer cells. Eur J Pharmacol 2011; 660: 268-74.

[113] Kenny PA, Enver T, Ashworth A. Receptor and secreted targets of Wnt-1/beta-catenin signalling in mouse mammary epithelial cells. BMC Cancer 2005; 5: 3.

[114] Han Z, Ni J, Smits P, et al. Extracellular matrix protein 1 (ECM1) has angiogenic properties and is expressed by breast tumor cells. FASEB J 2001; 15: 988-94.

[115] Breloy I, Pacharra S, Ottis P, et al. O-linked N,N'diacetyllactosamine (LacdiNAc)-modified glycans in extracellular matrix glycoproteins are specifically phosphorylated at subterminal N-acetylglucosamine. J Biol Chem 2012; 287: 18275-86.

[116] Hoogendam J, Farih-Sips H, van Beek E, et al. Novel late response genes of PTHrP in chondrocytes. Horm Res 2007; 67: 159-70.

[117] Funahashi H, Okada Y, Sawai H, et al. The role of glial cell linederived neurotrophic factor (GDNF) and integrins for invasion and metastasis in human pancreatic cancer cells. J Surg Oncol 2005; 91: 77-83.

[118] Liu Z, Kim JH, Falo LD Jr, You Z. Tumor regulatory T cells potently abrogate antitumor immunity. J Immunol 2009; 182: 6160-7.

[119] Sugimoto N, Oida T, Hirota K, et al. Foxp3-dependent and independent molecules specific for $\mathrm{CD} 25+\mathrm{CD} 4+$ natural regulatory T cells revealed by DNA microarray analysis. Int Immunol 2006; 18: 1197-209.

[120] Dubois B, Chapat L, Goubier A, et al. Innate CD4+CD25+ regulatory $\mathrm{T}$ cells are required for oral tolerance and inhibition of CD8+ $\mathrm{T}$ cells mediating skin inflammation. Blood 2006; 102: 3295-301

[121] Vocanson M, Hennino A, Cluzel-Tailhardat M, et al. CD8+ T cells are effector cells of contact dermatitis to common skin allergens in mice. J Invest Dermatol 2006; 126: 815-20.

[122] Shapira E, Brodsky B, Proscura E, et al. Amelioration of experimental autoimmune encephalitis by novel peptides: involvement of T regulatory cells. J Autoimmun 2010; 35: 98-106.

[123] Zhang Y, Bandala-Sanchez E, Harrison LC. Revisiting regulatory $\mathrm{T}$ cells in type 1 diabetes. Curr Opin Endocrinol Diabetes Obes 2012; 19: 271-8.

[124] Marazuela M, García-López MA, Figueroa-Vega N, et al. Regulatory $\mathrm{T}$ cells in human autoimmune thyroid disease. $\mathrm{J}$ Clin Endocrinol Metab 2006; 91: 3639-46.

[125] Maul J, Loddenkemper C, Mundt P, et al. Peripheral and intestinal regulatory $\mathrm{CD} 4+\mathrm{CD} 25$ (high) $\mathrm{T}$ cells in inflammatory bowel disease. Gastroenterology 2005; 128: 1868-78.

[126] Fontenot JD, Gavin MA, Rudensky AY. Foxp3 programs the development and function of CD4+CD25+ regulatory T cells. Nat Immunol 2003; 4: 330-6.

[127] Antiga E, Quaglino P, Volpi W, et al. Regulatory T cells in skin lesions and blood of patients with bullous pemphigoid. J Eur Acad Dermatol Venereol 2013 [Epub ahead of print].

[128] Antiga E, Quaglino P, Bellandi S, et al. Regulatory T cells in the skin lesions and blood of patients with systemic sclerosis and morphoea. Br J Dermatol 2010; 162: 1056-63. 
[129] Wang L, Yu J, Ni J, et al. Extracellular matrix protein 1 (ECM1) is over-expressed in malignant epithelial tumors. Cancer Lett 2003: 200: 57-67.

[130] Pauws E, Veenboer GJ, Smit JW, et al. Genes differentially expressed in thyroid carcinoma identified by comparison of SAGE expression profiles. FASEB J 2004: 18: 560-1.

[131] Chen H, Jia WD, Li JS, et al. Extracellular matrix protein 1, a novel prognostic factor, is associated with metastatic potential of hepatocellular carcinoma. Med Oncol 2011; 28 Suppl 1: S318-25.

[132] Bianchini G, Qi Y, Alvarez RH, et al. Molecular anatomy of breast cancer stroma and its prognostic value in estrogen receptor-positive and -negative cancers. J Clin Oncol 2010; 28: 4316-23.

[133] Han Z, Lin GJ, Chi FL, et al. The relationship between the extracellular matrix and the angiogenesis and metastasis of laryngeal carcinoma. J Otorhinolaryngol Relat Spec 2008; 70: 3528.

[134] Kreunin P, Urquidi V, Lubman DM, Goodison S. Identification of metastasis-associated proteins in a human tumor metastasis model using the mass-mapping technique. Proteomics 2004: 4: 2754-65.

[135] Millington GWM, Graham-Brown RAC. Skin and skin disease throughout life. In: Burns T, Breathnach S, Cox N, Griffiths C, Eds. Rook's Textbook of Dermatology. $8^{\text {th }}$ ed. Oxford: WileyBlackwell Publication 2010; pp. 21-9.

[136] Wlaschek M, Tantcheva-Poor I, Naderi L, et al. Solar UV irradiation and dermal photoaging. J Photochem Photobiol 2001; 63: 41-51.

[137] Varani J, Warner RL, Gharaee-Kermani M, et al. Vitamin A antagonizes decreased cell growth and elevated collagen-degrading matrix metalloproteinases and stimulates collagen accumulation in naturally aged human skin. J Invest Dermatol 2000; 114: 480-6.

[138] Lock-Andersen J, Therkildsen P, de Fine OF, et al. Epidermal thickness, skin pigmentation and constitutive photosensitivity. Photodermatol Photoimmunol Photomed 1997; 13: 153-8.

[139] Chung JH, Seo JY, Choi HR, et al. Modulation of skin collagen metabolism in aged and photoaged human skin in vivo. J Invest Dermatol 2001; 117: 1218-24.

[140] Kligman LH, Kligman AM. The nature of photoaging: its prevention and repair. Photodermatology 1986; 3: 215-27.
[141] de Rigal J, Escoffier C, Querleux B, et al. Assessment of aging of the human skin by in vivo ultrasonic imaging. J Invest Dermatol 1989; 93: 621-5.

[142] Bernstein EF, Chen YQ, Kopp JB, et al. Long-term sun exposure alters the collagen of the papillary dermis. Comparison of sunprotected and photoaged skin by northern analysis, immunohistochemical staining, and confocal laser scanning microscopy. J Am Acad Dermatol 1996; 34: 209-18.

[143] Van Hougenhouck-Tulleken W, Chan I, Hamada T, et al. Clinical and molecular characterization of lipoid proteinosis in Namaqualand, South Africa. Br J Dermatol 2004; 151: 413-23.

[144] Gambichler T, Skrygan M, Czempiel V, et al. Differential expression of connective tissue growth factor and extracellular matrix proteins in lichen sclerosus. J Eur Acad Dermatol Venereol 2012; 26: 207-12.

[145] Carli P, Moretti S, Spallanzani A, Berti E, Cattaneo A. Fibrogenic cytokines in vulvar lichen sclerosus. An immunohistochemical study. J Reprod Med 1997; 42: 161-5

[146] Morita A. Tobacco smoke causes premature skin aging. J Dermatol Sci 2007; 48: 169-75.

[147] Leung WC, Harvey I. Is skin ageing in the elderly caused by sun exposure or smoking? Br J Dermatol 2002; 147: 1187-91

[148] Martires KJ, Fu P, Polster AM, et al. Factors that affect skin aging: a cohort-based survey on twins. Arch Dermatol 2009; 145: 1375-9.

[149] Van Gansen P, Van Lerberghe N. Potential and limitations of cultivated fibroblasts in the study of senescence in animals. A review on the murine skin fibroblasts system. Arch Gerontol Geriatr 1988; 7:31-74

[150] Arredondo J, Hall LL, Ndoye A, et al. Central role of fibroblast alpha3 nicotinic acetylcholine receptor in mediating cutaneous effects of nicotine. Lab Invest 2003; 83: 207-25.

[151] Chamoto K, Gibney BC, Lee GS, et al. Migration of CD11b (+) accessory cells during murine lung regeneration. Stem Cell Res 2013; 10: 267-77.

[152] Amano S, Akutsu N, Matsunaga Y, et al. Importance of balance between extracellular matrix synthesis and degradation in basement membrane formation. Exp Cell Res 2001; 271: 249-62.

(C) Oyama and Merregaert; Licensee Bentham Open.

This is an open access article licensed under the terms of the Creative Commons Attribution Non-Commercial License (http://creativecommons.org/licenses/by$\mathrm{nc} / 3.0 /$ ) which permits unrestricted, non-commercial use, distribution and reproduction in any medium, provided the work is properly cited. 